\title{
O RELACIONAMENTO MÃE-BEBÊ PRÉ-TERMO APÓS A ALTA HOSPITALAR*
}

\author{
Gécica Gracieli Wust ${ }^{1}$, Cláudia Silveira Viera ${ }^{2}$
}

\begin{abstract}
RESUMO: Este estudo teve como objetivo descrever o relacionamento mãe-filho pré-termo após a alta da unidade de terapia intensiva neonatal, considerando-se que ambos passaram por privação de contato após o parto. Caracteriza-se como pesquisa qualitativa, do tipo estudo de caso. Constituíram-se em sujeitos do estudo quatro mães cujos filhos estiveram hospitalizados entre outubro e dezembro de 2008. Os dados foram coletados por meio de entrevista em visitas domiciliárias na primeira semana após a alta hospitalar; para a análise utilizou-se os preceitos da análise temática. Emergiu no estudo que o relacionamento mãe-filho pode ser visto sob três aspectos: estar junto em casa; a mudança na dinâmica familiar com a chegada do bebê; cuidando do recém-nascido em casa. Conhecer como se dá a interação mãe-filho, após a alta hospitalar, proporciona meios de cuidar contribuindo para o desenvolvimento cognitivo, afetivo e social do bebê e auxiliando a mãe no desenvolvimento de habilidades de maternagem.
\end{abstract}

PALAVRAS-CHAVE: Enfermagem; Relações mãe-filho; Vínculo.

\section{THE RELATIONSHIP BETWEEN MOTHER AND PREMATURE BABY AFTER ADMISSION TO HOSPITAL}

\begin{abstract}
This study had as its aim to describe the mother-premature baby relationship after discharge from a neonatal intensive therapy unit, considering that both pass through deprivation of contact after the birth. It is characterized by qualitative research, of case-study type. The study subjects were four mothers whose children were hospitalized between October and December 2008. The data were collected via interviews during home visits in the first week after hospital discharge; the precepts of thematic analysis were used for the analysis. From the study it emerged that the mother-child relationship can be understood from three angles: being together at home; the change in the family dynamics due to the baby's arrival; and caring for the new-born at home. Being familiar with the mother-child interactions after hospital discharge provides means of caring while contributing to the cognitive, affective and social development of the baby, and helps the mother to develop her maternal abilities.
\end{abstract}

KEYWORDS: Nursing; Mother-child relationship; Link.

\section{LA RELACIÓN MADRE-BEBÉ EN SITUACIÓN DE PREMATURIDAD DESPUÉS DE ALTA HOSPITALAR*}

RESUMEN: Este estudio tuvo como objetivo describir la relación madre-hijo en situación de prematuridad después de alta de la unidad de terapia intensiva neonatal, considerándose que ambos pasaron por privación de contacto después del parto. Se caracteriza como investigación cualitativa, del tipo estudio de caso. Los sujetos del estudio fueron cuatro madres cuyos hijos estuvieron hospitalizados entre octubre y diciembre de 2008. Los datos fueron recogidos por medio de entrevista en visitas en domicilio en la primera semana después del alta hospitalar; para el análisis fueron utilizados los preceptos del análisis temático. Se concluyó en el estudio que la relación madre-hijo puede ser vista bajo tres aspectos: estar junto en casa; el cambio en la dinámica familiar con la llegada del bebé; cuidando del recién nacido en casa. Conocer la interacción madrehijo, después del alta hospitalar proporciona medios de cuidar contribuyendo para el desarrollo cognitivo, afectivo y social del bebé y ayudando la madre y el desarrollo de habilidades maternas.

PALABRAS CLAVE: Enfermería; Relaciones madre-hijo; Vínculo.

*Artigo extraído de Pesquisa de Iniciação Científica 2009/2010 financiada pela Fundação Araucária de Apoio ao Desenvolvimento Científico e Tecnológico do Paraná

${ }^{1}$ Acadêmica de Enfermagem pela Universidade Estadual do Oeste do Paraná - Unioeste.

${ }^{2}$ Enfermeira. Doutora em Saúde Pública. Professora do Curso de Graduação em Enfermagem da Unioeste.

\section{Autor correspondente:}

Cláudia Silveira Viera

Universidade Estadual do Oeste do Paraná

R. Bétula, 124 - 85807-240 - Cascavel-PR

E-mail: clausviera@hotmail.com

Recebido: $17 / 11 / 10$

Aprovado: 11/04/11 


\section{INTRODUÇÃO}

A facilitação da proximidade e o contato físico precoce entre mãe e filho deve ser uma das ações prioritárias da equipe de saúde que atende essa díade, desde o período de parto e pós-parto, até sua inserção nos programas de puericultura na Atenção Primária à Saúde, após a alta hospitalar. Essa aproximação imediata é dificultada quando o recém-nascido está sujeito a algum tipo de comprometimento da sua saúde e hospitalização em uma Unidade da Terapia Intensiva Neonatal (UTIN).

Nessa situação, o período neonatal, no qual o enlace entre mãe e filho deveria ser fortalecido, torna-se um momento de conturbação afetiva diante da necessidade de separação temporária. Os pais passam a experimentar diversos sentimentos, em que a sensação de perda torna-se predominante nestes casos. O nascimento, na visão familiar, torna-se, por vezes, uma tragédia, pois as expectativas de um filho saudável é frustrada frente à complicação do recém-nascido(1).

Nesse contexto, o acompanhamento do recém-nascido pré-termo (RNPT) e sua família é um dos aspectos do cuidado de enfermagem que deve ser contemplado; o período na UTIN contribui para que o RNPT e a família estejam vulneráveis tanto a problemas físicos como emocionais. $\mathrm{O}$ estresse advindo da condição de prematuridade, as influências do ambiente da UTIN e as injúrias sofridas nesse período - o afastamento da família, dor, entre outros - são fatores que poderão produzir sequelas para o desenvolvimento do RNPT, assim como alterações nas relações afetivas entre mãefilho ${ }^{(2)}$.

Nos últimos anos houve acesso considerável de RNPT à UTIN, havendo incremento diário dos recursos tecnológicos que possibilitam a sobrevida de prematuros cada vez menores. Nesse contexto, o cuidado acabou por tornar-se fragmentado e tecnicista, emergindo então a necessidade de mudar o olhar para o recém-nascido hospitalizado. A Enfermagem brasileira deve ampliar o enfoque do cuidado na medida em que a assistência é estendida à família do RNPT e passa a se preocupar para além de salvar a vida da criança, mas também em propiciar-lhe qualidade de vida no futuro $^{(3)}$.

Entre os aspectos desse cuidado à família e ao RNPT, questiona-se como ocorre a continuidade do apego e a formação de vínculo mãe-filho frente à hospitalização, especialmente, ao vínculo após a alta hospitalar. Os conflitos gerados na aceitação do bebê imaginário frente ao RNPT real, associados às dúvidas quanto à sobrevivência do filho e a sentimentos de incapacidade, culpa e medo, são aspectos que podem interferir no relacionamento com o filho, mesmo que isso não ocorra de forma plenamente consciente para os pais, afetando a relação entre eles diretamen$\mathrm{te}^{(4-5)}$.

A quebra do vínculo inicial, devido à permanência no hospital, interfere no relacionamento mãe-filho em casa, no primeiro mês após a alta hospitalar? Para apreender o significado do cuidado foi objetivo desse estudo descrever o relacionamento mãe-filho após a alta da unidade de terapia intensiva neonatal.

\section{METODOLOGIA}

Este é um estudo de abordagem qualitativa do tipo estudo de caso, foi realizado com quatro mães que tinham RNPT hospitalizados em hospital público da região oeste do Estado do Paraná durante o período da coleta dos dados, ou seja, de outubro a dezembro de 2008. Os critérios de inclusão dos sujeitos no estudo foram: ser mãe de recém-nascido com idade gestacional entre 32 e 36 semanas e sem complicações genéticas e/ ou má-formação congênita; dar o aceite em participar do estudo; residir no município de localização do hospital do estudo.

A captação dos sujeitos ocorreu no período de hospitalização dos RNPT na UTIN do referido hospital. Nesse momento, agendava-se visitas domiciliárias para a primeira semana após a alta hospitalar com as mães que aceitassem em participar do estudo. Na primeira visita foram agendadas as próximas, sendo realizadas semanalmente, no primeiro mês após a alta hospitalar. Ao total foram realizadas 16 visitas domiciliárias, quatro com cada participante do estudo. A técnica de coleta de dados foi a entrevista gravada, tendo como questão norteadora "Como é para você estar em casa com seu filho prematuro?". A análise dos dados foi feita pela abordagem qualitativa, conduzida pela análise temáti$\mathrm{ca}^{(6)}$.

O estudo respeitou os preceitos Éticos da Pesquisa com Seres Humanos, sendo o projeto aprovado pelo Comitê de Ética e Pesquisa da Universidade Estadual do Oeste do Paraná e aprovado pelo parecer n. 324/2008. As participantes do estudo assinaram o Termo de Consentimento Livre e Esclarecido e seus nomes e o nome dos filhos foram mantidos em sigilo, sendo trocados por nomes fictícios que aparecem citados junto aos fragmentos de falas no texto. 


\section{RESULTADOS}

Do estudo emergiu que o relacionamento mãe-filho após a alta da UTIN pode ser visto sob três aspectos: estar junto em casa; a mudança na dinâmica familiar com a chegada do bebê e cuidando do RNPT em casa.

\section{Estar junto em casa}

Estar em casa com o filho significou para as mães segurança e bem-estar por poder ficar mais tempo ao lado do filho, e poder cuidá-lo. Este período foi definido como de muita emoção:

[...] foi um momento de emoção, muita emoção, depois que ele chegou [...] melhor coisa é ficar perto. (Daniele, mãe de Jeferson)

[...] muito bom [estar com o RNPT em casa], porque ficou internada e eu estava louca para ela vim para casa [...]. Ah, eu pensei 'agora não tem mais perigo', saiu daqueles aparelhos. (Rosa, mãe de Julia)

Contudo, o pouco contato entre mãe-filho durante a hospitalização propiciou sentimentos negativos nas mães, como tristeza; rejeição; estresse; impossibilidade de contato direto com o filho durante os primeiros dias na UTIN e a repercussão do nascimento prematuro, pois o filho tem aparência diferente da idealizada na gestação:

[...] foi um pouco melhor, melhorou bastante, quando chegou em casa [...]. Ah, do jeito que eu vi ele, fiquei assustada, que ele tava com banho de luz e tinha sorinho no pé. Me deu uma angústia, um negócio, ai eu falei 'não quero mais ver esse nenê na frente'[...]. (Violeta, mãe de Pedro)

No desenvolvimento do estudo, percebeu-se a reversão desse sentimento da mãe, devido ao apoio que recebeu da família, representado por cuidados do companheiro e da avó de Pedro, tornando mais fácil a aceitação do nascimento prematuro e iniciando a participação no cuidado do filho. Apesar das dificuldades encontradas pela família, a mãe demonstra o sentimento de ter o filho para si, de poder praticar os cuidados em casa, sentindo-se "mais mãe" do que quando estava no ambiente hospitalar:

[...] muito bom cuidar dele. Se eu pudesse ficava só cuidando dele, o dia todo. (Margarida, mãe de Anjinho)
[...] na UTI eu vi ele, mas não deixavam a gente ficar pegando, essas coisas [...]. E o sentimento em ter ele aqui é a melhor coisa. (Violeta, mãe de Pedro)

Estes sentimentos advêm do fato que no hospital não eram proporcionados momentos de intimidade entre mãe-filho. A ligação que as mães começaram a desenvolver na Unidade de Cuidados Intermediários Neonatais, presenciada neste estudo durante as visitas, certamente corroborou para a continuidade do desenvolvimento do apego no domicílio.

Durante as visitas emergiu a crença das mães em Deus:

[...] mas dai digo 'agora tô eu aqui, oh'! Graças a Deus deu tudo certo e a gente tá aqui. [...] ninguém, jamais acredita, mas eu falei 'o exame não mente', né? Então, é tudo por Deus. (Margarida, mãe de Anjinho)

Por meio dessa crença as mulheres buscam o fortalecimento para enfrentar a situação de conviver com o RNPT em casa. Os pais encontram, pela fé em um Ser Supremo, a causa da recuperação do filho doente.

\section{A mudança da dinâmica familiar}

$\mathrm{Na}$ visão das mães deste estudo, a mudança de rotina foi determinada como momento de adaptação entre elas e o filho, uma vez que a aproximação entre eles ficou dificultado na hospitalização. Nos primeiros encontros com o bebê, na UTIN, os sujeitos relataram dificuldades no cuidado, reflexo da falta de experiência e orientação por parte da equipe. Porém, nos primeiros dias com o filho em casa, a relação entre mãe e bebê começou a se intensificar.

O cansaço, a mudança de rotina de ter que acordar à noite para amamentar, as frequentes consultas com especialistas, foram aspectos que influenciaram a modificação do cotidiano familiar:

[...] cansativo acordar de madrugada para dar de mamar. Então, até você se acostumar, acordar, dar de mamar, e isso ser automático, tá sendo um pouquinho sofrido. [...] fazia quatro dias que tinha saído do hospital já estava correndo para baixo e pra cima [...] indo bastante em médico, um do ouvido, outro do olhinho e outro pros nervinhos dele. (Violeta, mãe de Pedro)

Ele dorme o dia inteiro, quando é de noite eu amanheço acordada com ele [risos] chora, tem vez que ele dorme, dai eu durmo um pouco [...]. Não deixa fazer meu 
serviço, nada. Até essa semana, tava lavando roupa, e tive que parar. Daí, minha sogra teve que terminar de lavar minhas roupas, porque ele chorava, chorava. Eu dava mama, parece que não adiantava. (Danieli, mãe de Jeferson)

Algumas famílias relataram as mudanças ocorridas em sua rotina durante a hospitalização, pela preocupação e necessidade de deslocamento diário:

[...] os dias que eu passei lá [UTIN] foram bem, só que foi cansativo, ficar o dia inteiro sentado, ou andando, né? Oito dias só andando, prá lá e pra cá. (Margarida, mãe de Anjinho)

Os primeiros dias em casa foram marcados por algumas dificuldades, como amamentar, trabalhar:

Ah, difícil foi dar mama. Minha amiga teve que ir tirando meu leite e eu fui dando [...] ela tirava na colher e dava na boca dele. (Danieli, mãe de Jeferson)

Eu também trabalho. Eu vendo. Agora que tô parada, ficou difícil, porque eu que sustento eles [família]. (Rosa, mãe de Júlia)

Após a gravidez complicada, o nascimento prematuro e os dias de internação na UTIN, a chegada em casa com o filho já no ambiente onde a mãe/família poderia praticar o cuidado, significou para elas $m u$ dança de vida:

Como diz meu marido, ele veio pra mudar nossas vidas [...]. Mudou completamente. (Margarida, mãe de Anjinho)

\section{Cuidando do RNPT em casa}

O cuidado do RNPT foi marcado pela presença da família, tendo as avós como coadjuvantes do cuidado:

O cuidado dele é bem bom. Cada passo vem minha mãe ou minha sogra, todo mundo ajudando. É o dia inteiro cuidando. Ai, ai escutam qualquer chorinho, tão correndo do lado dele. (Danieli, mãe de Jeferson)

Além da mãe, outros membros da família que compartilhavam o cuidado cotidiano do bebê - trocar fraldas, alimentação - também encontravam dificuldades nesses cuidados.
Ele está com uma assadurinha por causa da fralda. Eu acho que se continuar com a assadura, se a pomada não resolver, compramos pomada hoje, quer dizer a gente já estava passando pomada, mas receitaram uma mais forte. Mas, se não adiantar, eu vou pegar camiseta velha, e vou fazer pano de camiseta, esterilizo os panos de camiseta. (Maria, mãe de Violeta, avó de Pedro)

O conhecimento e a experiência das avós no cuidado do RNPT advêm de sua vivência de mãe. Esse aspecto precisa ser considerado pela equipe de saúde e auxiliar a família na tomada de decisão nos cuidados.

Percebeu-se, durante as visitas, o sentimento de ciúmes da mãe em relação ao bebê, a partir do momento em que começou a cuidá-lo. Este sentimento pode ser relacionado ao período de hospitalização e no qual a mãe não tinha contato direto. Então, estando em casa, ela aproveitava para ter o filho só para si:

Ah! Não deixo ninguém ajudar a cuidar dele [risos]. Fico com medo, né? Porque é uma criança diferente das outras. Até já me esqueci daquele ambiente [UTIN], agora eu tô tranquila dentro de casa, não dá vontade de largar ele um minuto. (Margarida, mãe de Anjinho)

Outro sentimento relatado foi o medo de realizar alguns cuidados de rotina, tais como dar banho, trocar fraldas, não saber identificar o choro do adoecimento da criança e ter que ser novamente hospitalizado, medo da asfixia durante o sono:

Ah, eu tem vez que começo a chorar também. A mãe [avó] falou que é normal, mas meu medo é ver ele assim chorando e não saber o porquê. (Danieli, mãe de Jeferson)

Na cama, com ele, eu nunca dormi. Eu morro de medo, eu sou muito grande [mãe fala carinhosa olhando para o bebê]. (Violeta, mãe de Pedro)

Tenho medo de dar banho, medo dela se afogar também. (Rosa, mãe de Júlia)

Medo, assim, que ele fique doente, que volte a ficar no hospital, porque é horrivel ter um filho naquele lugar, lá. (Margarida, mãe de Anjinho)

Foram citadas também dificuldades com o cuidado durante a hospitalização, em relação à falta de infor- 
mação da equipe de saúde:

[...] a gente foi ver ele. Ai, a moça falou que eu tinha que começar a dar de mamar e trocar ele. Só que eu não sabia fazer nenhum dos dois, porque lá na UTI não deixavam a gente ficar tendo contato com ele. Aí, no segundo dia eu achei meio sofrido [...] eu ia bastante ao banco de leite, tava indo bastante pras meninas me ajudarem. (Violeta, mãe de Pedro)

É preciso reconhecer quando a mãe está pronta para começar a cuidar de seu filho e iniciá-la no cuidado direto durante a hospitalização, para que não se sinta pressionada e tenha estresse, mas que aprenda algo que venha minimizar as dificuldades de cuidado no ambiente domiciliar.

A experiência do primeiro mês em casa é mostrada por meio da compreensão materna dos significados do parto prematuro, da internação do filho na UTIN e do convívio em casa com o RNPT. Nessa vivência, emana o sentimento de ser mãe e de como ocorre o relacionamento com o filho após a alta hospitalar:

Ah, desde o começo foi uma experiência muito boa. Cada vez, assim que se é mãe, que com ele intera quatro, você vai ficando cada vez mais velha, mais capaz de cuidar de um filho, entendeu? Porque os outros já estão grandes. E é a mesma coisa que eu tivesse o primeiro, porque nove, quase dez anos depois ele nasceu. Daí parece que é o primeiro filho, que eu estou aprendendo tudo de novo. Foi mais assim, por ele ter nascido antes. Assim, a gente tem mais cuidado, tem mais medo. Parece que qualquer coisa que a gente der pra ele tem que ter mais cuidado, entendeu? Mesmo que ele tenha boa saúde, mas a gente tem sempre a impressão que ele é diferente dos outros. (Margarida, mãe de Anjinho)

O depoimento acima retrata a experiência da maternidade, que mesmo para a multigesta, o sentimento de ser mãe é sempre novo, emergindo a relação do cuidado diferenciado devido à prematuridade do filho. $\mathrm{O}$ nascimento do filho e o primeiro mês em casa, na visão das mães, se traduziu em um misto de sentimentos de apreensão e alegria, retratando o relacionamento mãeRNPT no primeiro mês após a alta:

O nosso relacionamento com ele é maravilhoso. À noite, a gente dorme com o pensamento nele. Você dorme, mas o seu pensamento está nele, né? Eu colo- co o berço bem do meu ladinho. Aí, fiquei cantando à noite pra ele dormir [...]. Então, é assim emocionante o relacionamento de uma mãe com um filho recémnascido. É muito bom. (Margarida, mãe de Anjinho)

Os momentos difíceis, como ver seus bebês submetidos a tratamentos que desconheciam, bem como a impossibilidade de cuidar diretamente dos filhos, passar a gestação imaginando como seria quando chegasse a hora do parto e nem poder se preparar para o parto, contribuiram para que as mães elaborassem suas percepções diante da prematuridade.

Nesse contexto, o sentimento que essas mães têm quando se percebem em casa com o filho é de que o perigo maior da perda do filho passou e que ele venceu os primeiros obstáculos da prematuridade. O bebê não depende mais de equipamentos da UTIN para a sobrevivência, mas do cuidado e carinho de sua mãe. Agora é possível identificar a interação mãe-RNPT por meio da presença dos fatores de interação, partindo de mãe para filho como os toques, contato olho-a-olho, o tom da voz da mãe (sempre carinhoso e mais agudo), bem como os que partiam do filho para a mãe, tais como choro, calma ao permanecer no colo da mãe e o contato olho-a-olho ${ }^{(5)}$.

E como ele dorme é que não tem dor e não tem fome. 'Diga, olha como eu tô gordo olha' [mãe fala com voz carinhosa e aguda ao filho]. 'Eu sou o homem da minha mãe, eu sou o homem da minha mãe' [mãe segura bebê no colo e conversa com ele]. (Margarida, mãe de Anjinho)

O sentimento de alegria demonstrado pela mãe, por estar com o filho em sua casa neste primeiro mês, propiciou melhorias em seu relacionamento com o RNPT. E desse modo, possibilitou o fortalecimento do vínculo e interação entre ambos.

\section{DISCUSSÃO}

Ir para casa com um RNPT é sempre um obstáculo a ser transposto, não importa o quão experientes sejam seus pais, nem o quanto se preocupam com o filho. As primeiras semanas em casa tendem a ser um período de adaptação. Desse modo, os pais ficam sujeitos a sentimentos diversos como os identificados nas visitas neste estudo. Os primeiros dias em casa são marcantes e únicos, pois cresce a aproximação dos pais com os filhos, bem como a responsabilidade de cuidar. O pe- 
ríodo é permeado pelo prazer de cuidar, mas também pelas dificuldades decorrentes da adaptação ${ }^{(7)}$.

Ter o filho prematuro e enfrentar algumas situações indesejadas, como internação, além de provocar medo e insegurança, desorganiza o cotidiano dos pais e requer uma nova organização do modo de enfrentar a vida ${ }^{(7)}$. Estar em casa com o RNPT requer dos pais cuidado mais intensivo e, consequentemente, modificações na relação familiar, havendo reajustes para receber o novo membro. Nesse processo de adaptação os pais e familiares sentem-se inseguros no cuidado do bebê, bem como receiam uma nova internação ${ }^{(5)}$.

A família tem estrutura própria e estabelece entre seus membros vínculos afetivos, sociais e econômicos que constituem uma dinâmica singular, a qual está sujeita à modificações ao longo do curso de vida dessa família. Para tanto, a família precisa se reorganizar para restabelecer sua dinâmica familiar após a chegada do prematuro em casa.

Emergiram neste estudo aspectos que são considerados comuns à mãe que tem um $\operatorname{RNPT}^{(5,7)}$, tais como sentimento de fuga, medo, negação ao filho e o modo como a mãe reage ao ver seu filho submetido ao tratamento, tão frágil e conectado a equipamentos. Todos esses fatores associados podem, inicialmente, comprometer o vínculo entre mãe-filho, no entanto, os estágios pelos quais os pais passam para a formação do apego acontecem de forma diferenciada e eles precisam lidar com os diversos sentimentos que emergem nessa situação. Para facilitar a aceitação da situação e sua elaboração, os pais precisam de apoio tanto de sua família como da equipe de saúde dos diversos serviços que fazem parte de seu cotidiano.

É preciso, então, estabelecer rotinas nas UTIN e nos serviços de apoio para o acolhimento da família que experencia a prematuridade do filho, com vistas a facilitar o estabelecimento do vínculo entre mãefilho e família, uma vez que este é fundamental para o desenvolvimento do bebê. Entre essas rotinas, tem-se a participação da mãe eu família nos cuidados com o bebê ainda na UTIN, possibilitando a interação e estabelecimento do vínculo afetivo e a prática dos cuidados que serão realizados em casa, após a alta hospitalar. Ressalta-se que para essa participação ser efetiva são necessários estímulos táteis (toques e carícias) e auditivos (fala e canto). Porém, nem sempre a mãe/família é iniciada nos cuidados, e o preparo para a alta hospitalar ocorre no dia que recebe liberação para casa.

A equipe de saúde precisa conhecer a família e suas necessidades para auxiliá-la no relacionamento com o
RNPT no domicílio, tornando-a agradável e minimizando o desgaste sofrido pelas modificações na rotina familiar. Para auxiliar a mãe/família e sanar dúvidas quanto ao cuidado com o RNPT têm-se a realização de visitas domiciliárias pelos profissionais de saúde, principalmente, ao longo do primeiro mês após a alta hospitalar.

A mudança da rotina familiar vem como enfrentamento da situação estressante, pois a família passa por um momento de ajustamento e de adaptação familiar ${ }^{(8)}$. Cuidar de um recém-nascido é tido como ato próprio da natureza humana, sendo comum avós, filhos mais velhos, parentes e amigos ajudarem no cuidado ${ }^{(9)}$. Assim, o cuidar do RNPT em casa deve ter como suporte a rede social, na qual a equipe de saúde está inserida, e o apoio social, compreendido pelos familiares, amigos e membros da equipe de saúde. Mediante apoio e rede social eficazes, a mãe e família desenvolverão competências para cuidar; no entanto, neste estudo, verificou-se efetivo apoio social por parte da família, mas a rede social tornou-se ainda mais distanciada a partir da alta hospitalar.

Com base nessa compreensão, pode-se dizer que preparar os pais para a alta hospitalar implica em dotálos de competência para cuidar do filho e interagir com ele, quando se tem como eixo o cuidado centrado na família ${ }^{(9)}$. Assim, ao chegar a casa, os pais já adquiriram habilidades e segurança para dar continuidade a este cuidado. O acompanhamento da mãe/família na UTIN deve ter continuidade após a alta hospitalar, por parte dos profissionais de saúde.

Diante do exposto, percebeu-se as várias dificuldades encontradas pelas mães de RNPT na experiência de viver a prematuridade dos filhos. A crise inicial provocada pela separação, logo ao nascimento, assim como a interação prejudicada pelo pouco ou nenhum contato com o filho durante a hospitalização, constituem-se em fatores que contribuem para um comportamento materno e familiar alterados ${ }^{(10-11)}$.

A capacidade da mãe para desempenhar o cuidado é mais efetiva se houver segurança materna e relações positivas com o pai e com o restante da família ${ }^{(2,4,10)}$ o que pôde ser percebido neste estudo, em que a relação do apego foi se intensificando com o passar do tempo. Contudo, uma das mães do estudo não teve a presença do companheiro para auxiliá-la no cuidado com a filha. E em nenhum momento da visita ela nos contou sobre o pai da RNPT; esse fato mostra o déficit na estrutura dessa família, em que a mãe assume o cuidado de mãe e pai, contribuíndo para a mudança na dinâmica familiar. 
Neste caso, o auxílio à mãe para que se sinta capaz de prestar o cuidado ao filho é fundamental. A mãe que se sente mais segura no cuidado rotineiro com o filho, acompanhando seu crescimento, tem uma capacidade maior de desenvolver o apego. Da mesma forma, a criança que se sente segura nos braços da mãe poderá retribuir esse sentimento. Neste sentido, a visita domiciliar é potencial ferramenta de trabalho para fortalecer o cuidado familiar e a criação de vínculo entre a família e a equipe de saúde, prestando-se um cuidado de forma humanizada ${ }^{(12)}$.

Apreendeu-se, neste estudo, que a vivência em casa com o filho prematuro é um desafio para as mães, fase em que muitos sentimentos são experimentados. Nesse convívio, o cotidiano familiar vai se transformando a cada dia, bem como o desenvolvimento de ser mãe se torna real e o relacionamento mãe-filho vai se estreitando após o período de transição do hospital para casa ${ }^{(2)}$.

O modo de cuidar nos serviços de saúde, contudo, ainda se mostra frágil e fragmentado, havendo necessidade de organizar-se em rede e de oferecer seguimento qualificado, com maior interface entre os serviços especializados e a atenção primária. O cuidado prestado pela equipe de saúde reflete a sua vulnerabilidade quando apresenta um cuidado reducionista, ao invés de concebê-lo como processo interacional, contínuo e que ocorre em todos os espaços e momentos de contato com o usuário( ${ }^{(3)}$.

\section{CONSIDERAÇÕES FINAIS}

A experiência de ter um filho prematuro que permanece hospitalizado em UTIN por tempo indeterminado se traduz em uma situação geradora de estresse e crise familiar. A família, em especial a mãe do RNPT, precisa do suporte da equipe de saúde e dos serviços de saúde no seu cotidiano para enfrentar a situação adversa em que se encontra.

As equipe de saúde têm que utilizar estratégias que estimulem a interação e relacionamento, auxiliando a mãe/família no enfrentamento da situação da prematuridade, possibilitando minimizar sequelas, as quais podem ser resultantes do longo período de hospitalização e da própria condição de prematuridade.

A prematuridade, a hospitalização na UTIN e o cuidar do RNPT em casa constituem-se em fatos que causam impacto no cotidiano das famílias, exigindo revisão dos processos de interação e de funcionamento para que se adaptem à nova situação de vida. É necessário, então, que a equipe de saúde identifique os rearranjos da família e o que esta caracteriza como problemas nessa situação, para que tenha subsídios para o planejamento e implementação de cuidados direcionados a cada família. A finalidade é o cuidado efetivo e o relacionamento saudável entre mãe-filho e família, desde o momento de internação na unidade de terapia intensiva, até os primeiros meses em casa.

\section{REFERÊNCIAS}

1. Kenner C. Enfermagem neonatal. $2^{\mathrm{a}}$ ed. Rio de Janeiro: Reichmann e Affonso Editores; 2001.

2. Viera CS, Mello DF. O seguimento da saúde da criança pré-termo e de baixo peso egressa da terapia intensiva neonatal. Texto \& Contexto Enferm. 2009;18(1):74-82.

3. Viera CS, Mello DF, Oliveira BRG. Rede e apoio social familiar no seguimento do recém-nascido pré-termo e baixo peso ao nascer. Rev Eletr Enferm. 2010;12(1):11-9.

4. Guimarães GP, Monticelli M. A formação do apego pais/ recém-nascido pré-termo e/ou de baixo peso no método mãe-canguru: uma contribuição da enfermagem. Texto \& Contexto Enferm. [Internet] 2007;16(4) [acesso em 05 fev 2011]. Disponível: <http://www.scielo.br/pdf/tce/ v16n4/a06v16n4.pdf>

5. O desenvolvimento do apego: uma família em formação: Trad. de Dayse Batista. $4^{\mathrm{a}}$ ed. Porto Alegre: Artes Médicas; 1988.

6. Minayo MCS. O desafio do conhecimento: pesquisa qualitativa em saúde. $8^{\mathrm{a}}$ ed. São Paulo: Hucitec; 2004.

7. Tronchin DMR. A experiência de tornar-se pais de recém-nascido prematuro [tese]. São Paulo (SP): Universidade de São Paulo; 2003.

8. Lundqvist P, Westas LH, Hallstrom I. From distance toward proximity: fathers lived experience of caring for their preterm infants. J Pediatr Nurs. 2007;22(6):490-7.

9. Martinez JG, Fonseca LM, Scochi CGS. The participation of parents in the care of premature children in a neonatal unit: meanings attributed by the health team. Rev Latino-Am Enfermagem. 2007;15(2):239-46.

10. Cuidados maternos e saúde mental. Trad. de Vera Lúcia Baptista de Souza, Irene Rizzini. $4^{\mathrm{a}}$ ed. São Paulo: Martins Fontes; 2001. 
11. Bee H. A criança em desenvolvimento. $9^{\mathrm{a}}$ ed. Porto Alegre: Artmed; 2003. O desenvolvimento dos relacionamentos sociais. p. 348-77.

12. Drulla AG, Alexandre AMC, Rubel FI, Mazza VZ. A visita domiciliar como ferramenta ao cuidar da família. Cogitare Enferm. 2009;14(4):50-7. 